\title{
Clinton requests more this year for NSF, advanced technologies
}

Washington. The economic plan that US President Bill Clinton last week presented to Congress contains a $\$ 207$-million windfall for the National Science Foundation (NSF) and $\$ 103$ million more for the National Institutes of Standards and Technology (NIST).

The president's decision to increase significantly the budgets of these relatively small agencies in the current fiscal year (which ends on 30 September) is the first tangible evidence of his support for research programmes believed likely to pay off commercially. Energy-related research and atmospheric and oceanographic studies involving supercomputers would also benefit from an attempt to provide nearly $\$ 30$ billion by the end of 1994 for a range of projects through additional federal spending and tax incentives to industry. In contrast, the stimulus package contains nothing for the $\$ 10$-billion National Institutes of Health (NIH) or for basic research in the biomedical sciences except for \$9 million to continue NIH's role in developing a high-speed computer network serving several federal agencies.

The stimulus package is part of an economic plan described in a 145-page booklet entitled $A$ Vision of Change for America. Although most of the attention has gone to the new president's long-range attempt to reduce the $\$ 350$-billion annual federal deficit through a combination of tax increases and spending cuts, the short-term effect would be to restore more than half of the $\$ 340$ million increase that NSF requested for 1993 but which was rejected by Congress.

The booklet also provides details of parts of the budget for fiscal year 1994 that the president will submit to Congress on 23 March. This information, normally a closely guarded secret, is being disclosed prematurely this year because of the administration's desire to show what it is doing to stimulate the economy (see next page).

NSF intends to spend about half of its supplementary appropriation, if it is approved by Congress, on five presidential initiatives that it was not able to fund fully after its research budget for 1993 was reduced by $\$ 13$ million, to $\$ 1.86$ billion. (NSF's total budget is $\$ 2.75$ billion, which includes science education and the Antarctic programme.) Those initiatives advanced materials and processing, biotechnology, high performance computing, global change and advanced manufacturing were scheduled to grow by as much as 50 per cent, and the additional funds will allow NSF to come close to its original target.

Most of the rest will be spread among the foundation's core research programmes and is expected to go towards increasing the size of existing grants and for funding requests for instrumentation. Some $\$ 19$ million has been allocated to developing software to solve computational problems relating to research on health care costs. None of the money is expected to go to science education or to the repair of academic research facilities because money for those programmes is typically stretched out over several years.

Although NSF officials consider that distribution to be fair and consistent with the president's desire to stimulate the economy quickly, many basic researchers are still smarting from reductions made in the core programme that were taken to make room for the five high-profile, interdisciplinary initiatives. They feel that NSF should stick to funding the best investigatorinitiated science, a mission endorsed by the recent Commission on the Future of NSF (see Nature 360, 285; 1992).

The other big scientific winner this year is the Department of Commerce, for which an additional $\$ 262$ million has been requested. The additional funds for NIST will more than double its existing Advanced Technology Program (ATP), which this year has $\$ 68$ million to spend on industrial research, by single companies or consortia, that is not as yet ready for commercialization. The programme, begun in 1990 , has funded 60 projects involving an estimated $\$ 400$ million in research over the next five years. It requires companies to at least match the federal contribution.

The approach is one favoured by the Clinton administration because the ideas come from industry and undergo careful review by government scientists. By coincidence, the fourth round of proposals were due on 24 February, and agency officials say that they could spend some of the supplementary funds, once approved by Congress, simply by going further down the list of proposals that have passed muster. A fifth round of proposals, beginning in the spring, is a distinct possibility as well.

Also within Commerce, the National Oceanic and Atmospheric Administration would get an additional $\$ 81$ million this year to buy high-performance computers for facilities such as the Forecast Systems Laboratory in Boulder, Colorado, and the National Meteorological Center in Suitland, Maryland. Another agency winner is the tiny National Telecommunications and Information Administration, which would receive $\$ 64$ million more this year to begin developing an "information highway" linking businesses, schools and government agencies. The Department of Energy would get $\$ 47$ million more to match industrial interest in the efforts of its national laboratories through so-called CRADAs (Cooperative Research and Development Agreements) with laboratory scientists.

But the rapid growth of research programmes such as ATP presents a dilemma for Clinton: although he has promised to pare the federal work force by 100,000 , greater government spending requires additional staff. The NSF director, Walter Massey, has complained bitterly in recent years that the agency has insufficient resources to handle its rising work load, but the additional spending comes without any new staff positions. And although ATP officials say that the staff need not grow as rapidly as the budget, it is undeniable that peer review takes time and costs money.

Jeffrey Mervis \& Tony Reichhardt

\section{Restructuring British science}

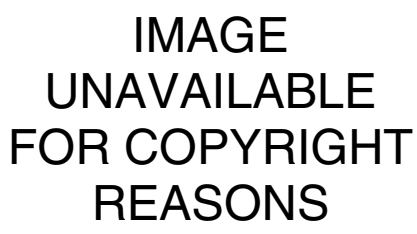

Sir Graham Hills of the University of Strathclyde drew a distinction between research inputs and outputs at a meeting last week in Edinburgh cosponsored by the city's international science festival and Nature. Details on page 681. 